\title{
Procedure and layout for the development of a fatigue test on an agricultural implement by a four poster test bench
}

\author{
M. Cutini, C. Bisaglia
}

\author{
Consiglio per la Ricerca e la Sperimentazione in Agricoltura, Unità di Ricerca per l'Ingegneria \\ Agraria, Laboratorio di Treviglio (BG), Italy
}

\begin{abstract}
The increasing demand in agricultural vehicles' power requirements, payloads and driving speeds increases issues related to tractors and farm implements exposure to solicitations. One of the main factors to be taken into account for fatigue test developing on agricultural machines is the heterogeneity of the environment and activity in which the tractor operates. In particular, for contractors the use in transport conditions both on terrain and road becomes important. As far as transport is concerned. factors mainly affecting solicitations on carried implement are soil profile roughness, tractor settings and forward speed. In this paper, CRA-ING laboratory of Treviglio, Italy, together with Frandent Group s.r.l. (Osasco, Italy), analyse the possibility of creating a solicitation profile by means of one four poster test bench for fatigue test on a carried implement simulating transport conditions. Accelerations at the hubs of the tractor were acquired during transport on terrain and reproduced with one electro-hydraulic four posters test bench on one dummy of a tractor developed for carrying the implement. Artificial bumps were mathematically created and introduced in the time history to simulate squares solicitations. Twelve hours of test were carried out. This experience confirmed the possibility of carrying out laboratory fatigue test on agricultural implements by reproducing specific field conditions solicitations with four poster test bench.
\end{abstract}

Correspondence: Maurizio Cutini, Consiglio per la Ricerca e la Sperimentazione in Agricoltura, Unità di Ricerca per l'Ingegneria Agraria, Laboratorio di Treviglio, via Milano 43, 24047 Treviglio (BG), Italy.

Tel/Fax.: +39.0363.49603.

E-mail: maurizio.cutini@entecra.it

Key words: vibration, solicitation, tractor.

Contributions: the authors contributed equally.

Conflict of interests: the authors declare no potential conflict of interests.

Conference presentation: this paper was presented at the $10^{\text {th }}$ AIIA Conference: "AIIA13 - Horizons in agricultural, forestry and biosystems engineering”, Viterbo, University of Tuscia, Italy, on September 8-12, 2013.

(C) Copyright M. Cutini and C. Bisaglia, 2013

Licensee PAGEPress, Italy

Journal of Agricultural Engineering 2013; XLIV(s2):e81

doi:10.4081/jae.2013.s2.e81

This article is distributed under the terms of the Creative Commons Attribution Noncommercial License (by-nc 3.0) which permits any noncommercial use, distribution, and reproduction in any medium, provided the original author(s) and source are credited.

\section{Introduction}

When normal conditions of use are concerned, irregularity of working terrains and forward speed are the most important causes of vibrations transmitted to agricultural tractors (Scarlett et al., 2007) with subsequent tool oscillation and work quality impairment (Cutini et al., 2011).

For several years tires have been the main element for mechanical vibrations attenuation on agricultural tractors : their effectiveness depends on factors such as eccentricity, load, resonance frequency, and elasticity characteristics (Nguyen et al., 2011; Sherwin et al., 2004;

Park et al., 2004; Taylor et al., 2000).

This phenomenon originates from the fact that the tire can be modeled as a series of radial and contiguous spring elements subjected to compressing and recovering forces when entering and exiting the road contact area (Witzel et al. 2011; Pacejka, 2010). Variations in the spring constants cause variations in the compressive and restorative forces as the tire rotates.

These forces variations run from tire centre toward the tread, and from the roadway through the tire centre toward the vehicle affecting handling and comfort.

So most of the studies have been directed to the tires' properties, dumping systems and/or their interaction.

However, as aforementioned, in agricultural machines an important factor characterizing the amplitude and frequency of vibrations is represented by the environment, in particular by the soil unevenness.

Soil unevenness has a stochastic character; its deformation has a non-linear, visco-elastic-plastic behaviour and its condition depends on a wide range of parameters (cultivation, cropping/tillage history, texture, organic residue, drainage conditions, etc.) so that it is almost impossible to standardize testing conditions in fields.

To analyze the effect of the surface on the vehicle is necessary to obtain the displacement or the accelerations acting under the tires.

Actually it's possible to measure forces at the hubs but it considers the contribute of the tires. Using measured soil profiles (obtained for example with optical technology) as system inputs is not sufficiently precise and repeatable because of soil deformations.

The most common existing approach (Anthonis, et al. 2007; Bisaglia et al., 2006) consists in an iterative methodology. During the field test, accelerations are measured at specific locations of the machine (usually at the hubs), then the machine is put on a test bench and the actuators of the bench are driven in order to create, by deconvolution method, input signals so that sensor signals match with the measurements obtained in the field.

The project foresees to:

1) acquire, during transport on field, time histories representatives of severe conditions,

2) reproduce these situations in laboratory at a four poster test bench,

3) create a "standard" time history,

4) replicate it for a required number of hours. 


\section{Theoretical considerations}

An iterative deconvolution method is a computerized control technique that enables to duplicate vehicle or component responses measured during field testing in laboratory conditions. The calculation of the control signals for the actuator of the test bench, called "drive signals", is a multivariable tracking problem, currently solved with the so-called iterative deconvolution (ID) procedure (Soderling et al., 1999), which is an off-line iterative feed forward procedure where drive signals are updated based on the measured frequency response function matrix (FRF) of the test arrangement and on the tracking errors obtained in the previous iteration.. During laboratory tests the Remote Parameter Control (RPC®) software from MTS Systems Corporation has been used. The drive signals obtained with this procedure can be considered an approximation of the real field surfaces subject to deformations.

The following steps represent a brief overview of the process:

1. Acquisition of road or service data: to record the road data, transducers are placed on the component and/or vehicle at sites remote from the input forces. These transducers measure accelerations, strains, or displacements. Field or service history data are recorded in either analog FM tape format or digital format. Typically, the number of transducers used for data acquisition exceeds the number of control channels on the simulator.

2. Transfer of (digitized) data to the personal computer.. After the data are recorded and digitized, they are transferred to a Windows based computer for analysis and editing to shorten the test time.

3. Measurement of the system frequency response function: a random noise drive signal is generated to drive the test system and measure its response. The response information is then used to calculate the system model.

4. Estimation (calculation) of the initial drive signal: during this step, the system model measured in Step 3 and the desired response time history from Step 2 are used to create an estimation of the initial drive signal.

$$
\begin{gathered}
\text { Desired signal } \times \text { FRF-1 } \times \text { gain }=\text { initial drive estimate } \\
0<\text { gain }<1
\end{gathered}
$$

5. Performing iterations. Because the test system (which includes the mechanical fixturing, hydraulics, and test specimen) is nonlinear and may have some inherent cross coupling, the difference between actual and desired time history responses is repeatedly measured to correct the subsequent drive files. This results is one drive signal inducing the desired response when used to command the test system.

6. Testing (i. e. durability). Once suitable drive signals are derived they are used as controller input commands to perform durability tests.

\section{Materials and methods}

Four terrain test bench differing for roughness and hardness, one agricultural tractor and one carried combined implement were used for these tests.

The worst case scenario was selected and reproduced in laboratory. The displacement of the plates defined the simulation of the vertical input of the fields' surfaces.

Evaluations were made with the manufacturer for choosing the level of amplitude of the time history respect to the nominal $100 \%$ of the field.

\section{Tractor and implement}

The test was carried out on one combined implement, harrow and seeder (Table 1).

The implement was carried by a four wheel drive tractor of $116 \mathrm{~kW}$ during test on field to acquire acceleration data from the four hubs.

\section{Terrain test bench}

The solicitation acting on the implement has been evaluated testing the machine on four different terrain surfaces chosen as test bench.

The adopted operations and the surfaces were:

- $\quad$ farming road (forward speed till $25 \mathrm{~km} / \mathrm{h}$ max);

- farming road on maize terrain cultivation (forward speed till 15 $\mathrm{km} / \mathrm{h} \max$ );

- $\quad$ on the transverse way of the sorghum cultivation (forward speed till $25 \mathrm{~km} / \mathrm{h} \max )$;

- $\quad$ on the transverse way of the maize cultivation (looking for the speed inducing tires' resonance).

The last condition was chosen as worst case scenario, in particular the conditions of the lanes were of $0.7 \mathrm{~m}$ distance and $0.14-0.17 \mathrm{~m}$ depth and the forward speed causing tires' resonance was $6 \mathrm{~km} / \mathrm{h}$ (Figure 1).

Table 1. Characteristics of the tested vehicle.

\begin{tabular}{llcc} 
Machine & \multicolumn{3}{c}{ Characteristics } \\
Tractor & Type & & 4 WD \\
& Power $(\mathrm{kW})$ & & 116 \\
& Mass & Front & 2450 \\
& with implement & Rear & 7950 \\
& $(\mathrm{~kg})$ & Total & 10400 \\
Harrow: & Width $(\mathrm{m})$ & & 3 \\
& Mass (kg) & & 1400 \\
\hline \multirow{2}{*}{ Seeder } & Width (m) & & 3 \\
& Mass (kg) & Machine & 900 \\
& & Ballast & 1000 \\
\hline
\end{tabular}

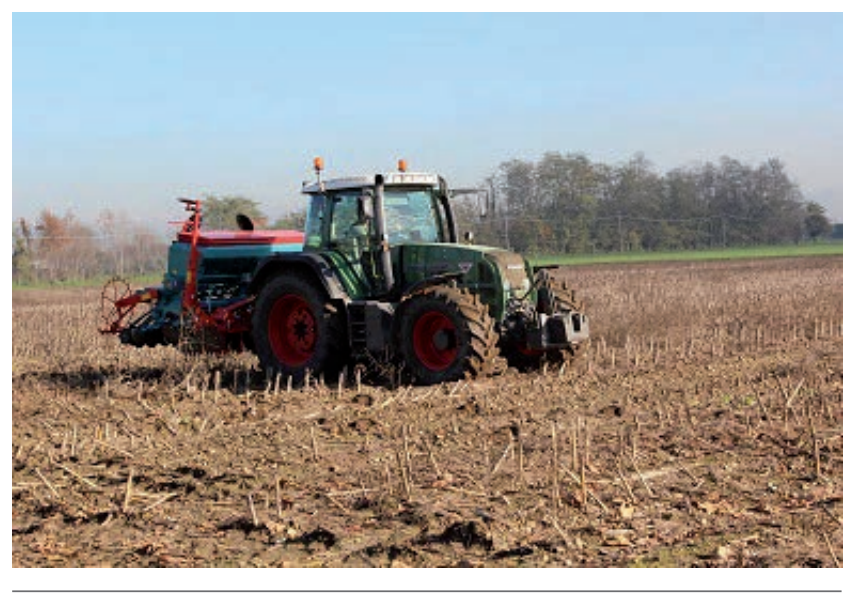

Figure 1. The tractor with the implement on the transverse way of the maize lanes. 


\section{The dummy tractor}

A dummy of tractor was developed. It consists of a front axle of a 100 $\mathrm{kW}$ tractor joined to a rear axle of a $200 \mathrm{~kW}$ tractor by two iron beam HEB 240x240x17 and two plates of $40 \mathrm{~mm}$ width. Its rear was equipped with a three point linkage system, category 3 .

Tires were $340 / 85$ R28 on the front and $650 / 65 / 38$ on the rear, the wheelbase was $2965 \mathrm{~mm}$, the masses of the unloaded dummy were $1250 \mathrm{~kg}$ on the front, $2280 \mathrm{~kg}$ on the rear for a total weight of $3530 \mathrm{~kg}$.

During the test $3400 \mathrm{~kg}$ of ballast were fitted on the front axle (Figure 2).

\section{Four poster test bench}

The CRA-ING four-poster test bench is specifically designed to test large and heavy vehicles up to $15 \mathrm{t}$ in off-road low-medium range forward speed conditions.

The stand is composed of a seismic mass of the weight of $408 \mathrm{t}$, isolated from the ground by means of pneumatic springs; four servohydraulic actuators articulated for wheel-base/track adjustment on the seismic mass and supporting four vibrating plates upon which the tires of the vehicle are placed; a power hydraulic and a control unit, including a computer-based controller and a data acquisition unit.

Each actuator is controlled in position (up to a frequency of $100 \mathrm{~Hz}$ and a peak-to-peak amplitude of $250 \mathrm{~mm}$ ) and excites one tire of the vehicle in vertical direction.

The displacements of the actuators are measured through linear variable differential transformer (LVDT) transducers, whose output signals are acquired and recorded.

\section{Measure instrumentation}

The vehicle has been instrumented with a set of four piezo-electric monoaxial accelerometers (range $\pm 50 \mathrm{~g}$, sensitivity $100 \mathrm{mV} / \mathrm{g}$ ) to measure the wheel hubs vertical acceleration and a triaxial seat accelerometer (range $\pm 50 \mathrm{~g}$, sensitivity $100 \mathrm{mV} / \mathrm{g}$ ) placed in correspondence of the seat surface to evaluate operator comfort.

\section{Results}

The roughness of the surface combined with the forward speed causes the excitation of the frequencies of the elastic parts and characteristic of the vehicle: tires, cab support, pitch, roll, etc...

The most severe solicitation acquired on the implement is characterized by the pitch of the tractor. This is further enhanced by the weight of the implement itself overhanging on the rear.

The spectrum of the acceleration at the front left hub, and characterizing the pitch, is reported in figure 3 (Des_FL).

It's possible to see the acceleration at about $2 \mathrm{~Hz}$ both on the front and on the rear axle.

The reproduction of the time history (TH) at the test bench has been addressed to obtain the main content in frequency acting on the whole vehicle. The time history of interest was reproduced with a mean RMS error of 38 (dimensionless) on the four channels (hubs). An example of the accuracy of the induced acceleration to field data is reported in Figure 3 with reference to the left channel. The final output of the signal reproduction process is the $\mathrm{TH}$ of the vertical displacement of the plates. Figure 4 shows that the spectrum of the obtained TH, with one high energy peak at $1 \mathrm{~Hz}$ can contribute up to $4 \mathrm{~Hz}$.

The first evaluation of the effect on the vehicle underlines the linearity of the solicitation or, on the contrary, the absence of shock on the implements that could happen as consequence of one not linear response of the vehicle to an obstacle.

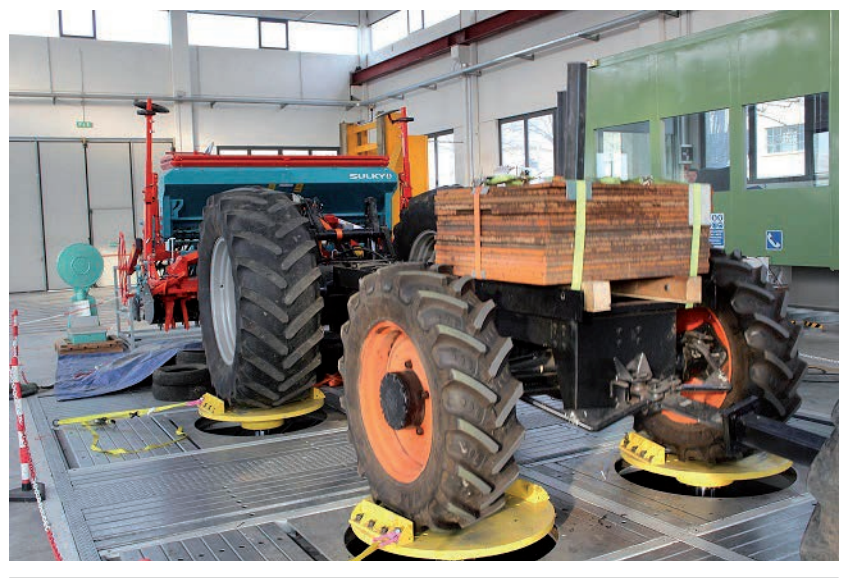

Figure 2. The test layout with the dummy tractor.

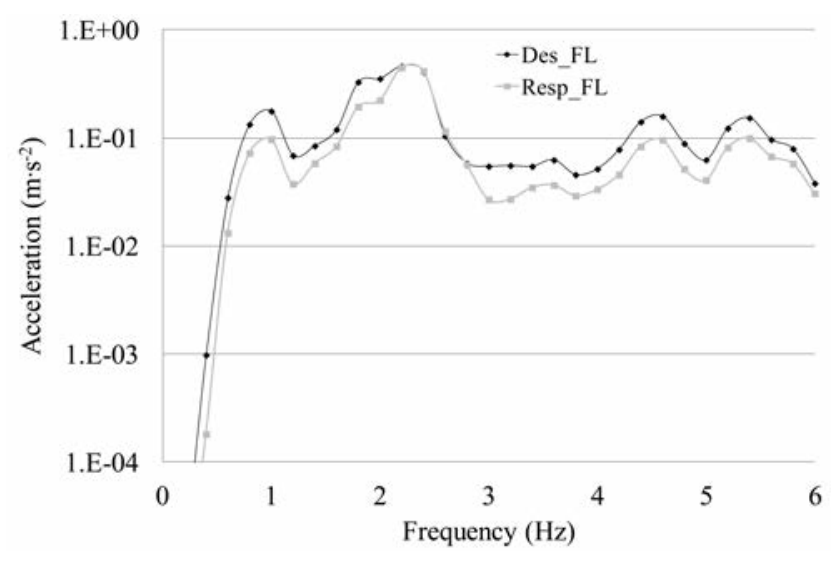

Figure 3. Example of the reproduction of the time history as frequency on the front left hub.

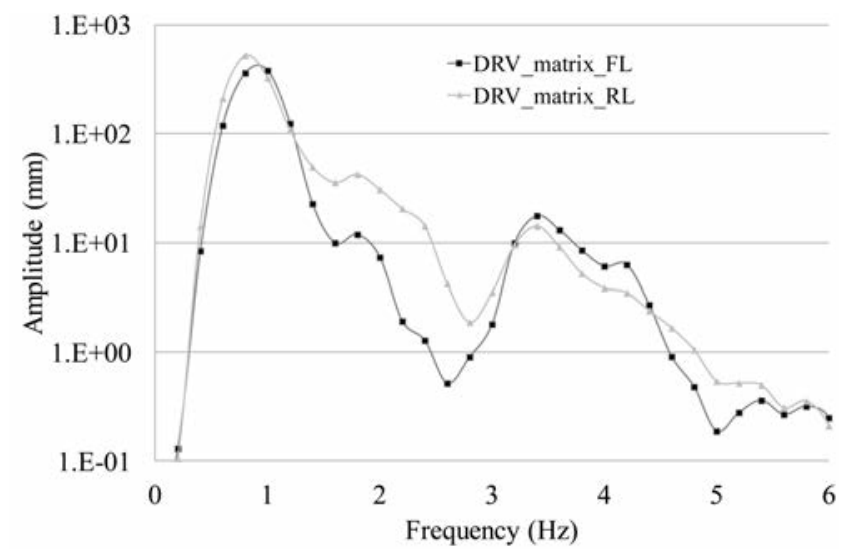

Figure 4. The spectrum of the displacement of the plates of the reproduced TH. 
For this reason artificial solicitations simulating the effect of bumps have been developed exciting the pitch of the tractor on the front tires by a $4 \mathrm{~Hz}$ sine, and combining it with a rear sine of $2 \mathrm{~Hz}$ not in phase. The result is shown in Figure 5.

Combining the reproduced TH with the bumps artificially obtained, it was possible to produce the desired solicitation that resulted in a cycle length of $55 \mathrm{~s}$. (Figure 6)

While performing simulation tests, the amplitude of the reproduced solicitation has been tested at $80 \% ; 90 \% ; 100 \% ; 105 \% ; 112 \%$ of the acquired one. The implement has been tested both empty and full with sand simulating the presence of seeds in the hopper. According to observations, working at $105 \%$ of the amplitude was chosen to carry out the fatigue test with bumps set at $16 \mathrm{~mm}$.

The test with the setting of the implement without ballast resulted more severe.

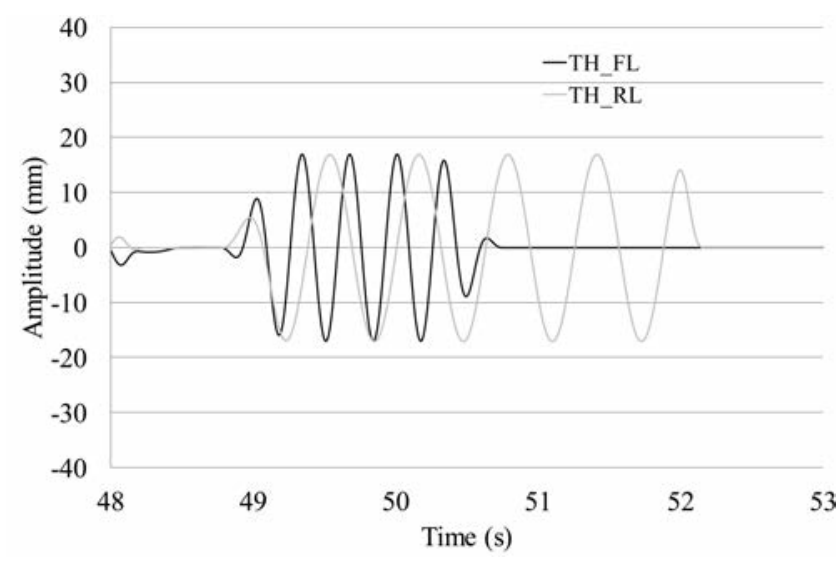

Figure 5. The developed bump for simulating vertical shock.

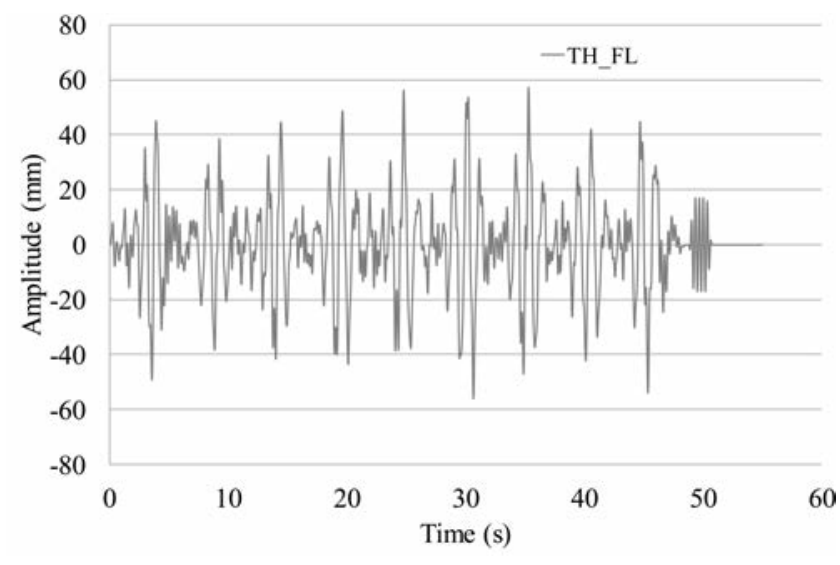

Figure 6. Graphic representation of the developed TH.

\section{Conclusions}

A combined implement, carried on a tractor, has been conducted in different fields and conditions for determining the solicitations considered severe for mechanical durability of the implement itself.

Among the time histories acquired during these real conditions of transport on terrains the most representative in terms of mechanical solicitations was selected. This last has been reproduced at an electrohydraulic four poster on a dummy of tractor especially developed for the implement couplement. Moreover, artificial bumps $16 \mathrm{~mm}$ height were introduced in the time history for simulating not linear solicitations as shocks.

The possibility of carrying out a fatigue test on a carried implement simulating the transport condition by a four poster test bench has been verified. Key aspects of the trial are resulted the choice of the conditions to reproduce both in terms of spectrum and amplitude.

\section{References}

Anthonis J., et al. 2007. Feedback Approach for Reproduction of Field Measurements on a Hydraulic Four Poster. Biosystems Engineering. 2007. 96(4), pp. 435-445.

Bisaglia C., Cutini M., Gruppo G., Assessment of vibration reproducibility on agricultural tractors by a "four poster test stand", proceedings of the XVI CIGR. EurAgEng 2006. 64th VDI-MEG and FAO joint "World Congress - Agricultural Engineering for a Better World", Bonn, Germany, September 3-7. 2006. pp.1-6.

Cutini M., Bisaglia C., Romano E., Measuring the radial eccentricity of agricultural tires for ride vibration assessment. Proceedings of the 39. International symposium on agricultural engineering "Actual tasks on agricultural engineering”, p. 63-72 (ISSN 1333-2651), 2225 February 2011, Opatija, Croatia.

Nguyen V. N., Inaba S., Effects of tire inflation pressure and tractor velocity on dynamic wheel load and rear axle vibrations, Journal of Terramechanics, 2011, vol.48, pp.3-16

Pacejka H. B. (2010) Tyre and vehicle dynamics. Oxford, Butterworth Heinemann

Park S., Popov A. A., Cole D. J., Influence of soil deformation on off-road heavy vehicle suspension vibration, Journal of Terramechanics, 2004, vol.41, pp.41-68

Scarlett A. J., Price J. S., Stayner R. M., Whole body vibration: Evaluation of emissions and exposure levels arising from agricultural tractors, Journal of Terramechanics, 2007, vol.44, pp.65-73

Sherwin L. M., Owende P. M. O., Kanali C. L., Lyons J., Ward S. M.. Influence of tyre inflation pressure on whole-body vibrations transmitted to the operator in a cut-to-length timber, Applied Ergonomics, 2004, vol.35 (3), pp.235-261

Soderling, S., Sharp, M. and Leser, C. 1999. Servo Controller Compensation Methods Selection of the Correct Technique for Test Applications. VII International MobilityTechnology Conference \& Exhibit. Sao Paulo, Brazil : s.n., 1999. pp. 30-35.

Taylor R. K., Bashford L. L., Schrock M. D., Methods for measuring vertical tire stiffness, Transactions of the ASAE, 2000, vol.43 (6), pp.1415-1419

Witzel P., Bottinger S. (2011), Upgrading of the Hohenheim Tyre Model to a radial approach, Landtechnik, 2.2011, 144-146 